\title{
Bitcoin Investment Behaviour: A Pilot Study
}

\author{
Haneffa Muchlis Gazali, Che Muhamad Hafiz Bin Che Ismail, Tamrin Amboala \\ Dep of International Finance, Universiti Malaysia Sabah Labuan International, Labuan, Malaysia \\ haneffa@ums.edu.my \\ Dep of Islamic Banking and Finance, International Islamic University Malaysia, Kuala Lumpur, MALAYSIA \\ cmhafiz86@gmail.com \\ Dep of Computing and Informatics, Universiti Malaysia Sabah Labuan International, Labuan , Malaysia \\ ramdzantrn@yahoo.com
}

\begin{abstract}
The evolution of blockchain technology that promotes decentralised peer to peer electronic cash system named as Bitcoin is becoming trending across the globe. Although the Bitcoin price is extremely volatile, the popularity of bitcoin is seemingly unambiguous. The Bitcoin trending has garnered a serious attention from the public, media and the academia. Hitherto, no research has yet systematically investigated the factors influencing the intention to invest in Bitcoin. Thus, the objective of this study is to identify the factors that influence the intention to invest in Bitcoin. An online survey was distributed via the email to the target respondents, those who have basic knowledge on Bitcoin investment. After three weeks of data collection period for pilot study, 45 samples were gathered to be tested further. Using the SPSS programme, the data were analysed through reliability test and factor analysis. The results of the study indicate that the items are valid and reliable. The exploratory factor analysis also discloses that the sampling is satisfactory. Being limited preliminary analysis, this study lacks the empirical evidence to confirm the relationships between the studied variables. Therefore, in future an adequate and bigger sample is needed to establish the empirical support on the associations of the studied variables.
\end{abstract}

Keywords—Bitcoin; Theory of Reasoned Action (TRA); Financial Risk Tolerance; Perceived Benefit

\section{INTRODUCTION}

Virtual currency or well-known as cryptocurrency has become a phenomenon around the world. Its volume of transactions has increased since 2014 as the investors scrambled to jump into the bandwagon to gain high profit in a short period of time. There is opinion indicating that cryptocurrency will replace fiat money in future. As the latest innovation in virtual currency is creating the digital money that serves peer-to-peer payment system in a store value [1]. Satoshi Nakamoto has introduced a system for electronic transaction back in 2009, known as Bitcoin.

BTC is the unit currency for Bitcoin. Bitcoin is the digital assets that can be transferred securely via cryptography. However, Bitcoin is different from the bank account balance, government fiat money or commodity money. This digital money is not under anyone's liability and not redeemable for any fiat money [2]. As the paper specifies, Bitcoin refers to virtual currency which has no physical representation such as fiat money [3]. The issuance of Bitcoin coins come from various parties such as individuals, organizations and firms.

In April 2018, the circulation of Bitcoin in the market is about 257 million with a trade value of 1 billion [4] Researcher claims that the cryptocurrency market is still in its infancy stage and is inefficient as it is a new investment asset [5]. Nevertheless, the acceptance of Bitcoin is rapidly increasing [6]. This is due to the features of Bitcoin system which is claimed to be more flexible, private and less amenable to regulatory oversight compared to any other methods of payment [7]. Despite all the features of cryptocurrency, Bitcoin has a number of risks involved such as price volatility, exchange rate risk, future legislation, theft or loss, third-party reliability and e-commerce vulnerabilities. In fact, cryptocurrencies have the tendency to be used in black market which can lead to financial disaster in financial market if not properly regulated. Heretofore, no research has yet systematically investigated the factors that influence users' intention to invest in cryptocurrency. The objective of this study is to identify the factors influencing the intention to invest in bitcoin. This paper extends the applicability of Theory of Reason Action (TRA) by incorporating perceived risk and perceived benefits in cryptocurrency investment context.

The paper written as followed: elaboration on TRA and followed by the discussion on theoretical model, research methodology and findings. The final part explains the contributions, implications and limitations of the study.

\section{THEORY OF REASONED ACTION}

Fishben and Ajzen have found a model that captures the relationship between beliefs, attitudes, intention and 
behaviour known as the Theory of Reasoned Action (TRA) [8][9]. There are two basic determinants in TRA which are attitudes and subjective norm. The function of TRA is to predict a person's intention based on one's personal in nature towards behaviour and the latter is reflecting subjective norms in society [10], [11]. Attitude represents an individual's general feeling of positive or negative evaluation towards performing particular behaviour [9] Meanwhile, the subjective norm is a function of belief that represents an individual's perception of the most important people thinking that he or she should perform that kind of behaviour [9]. These beliefs which could be defined as normative belief are underlying a person's subjective.

Normally the TRA is applied to understand a wide range of consumer behaviour such as predicting intention to choose halal products [11][12], Islamic home financing [13] and depositors' withdrawal behaviour in Islamic Banks [10]. This study uses the TRA based on two reasons. Firstly, past empirical researches have massively employed TRA in several different contexts of areas. Nonetheless, in cryptocurrency investment, there is yet a study using TRA to explain the intention in cryptocurrency investment. No previous study has assessed the TRA from the cryptocurrency investment perspective. Secondly, this study adapts TRA due to a lot of literature supports available. Hence, it is useful to study and investigate the extended version of TRA by incorporating financial risk tolerance and perceived benefits to give better prediction for consumer intention to invest in cryptocurrency. Figure 1 depicts the original framework of TRA.

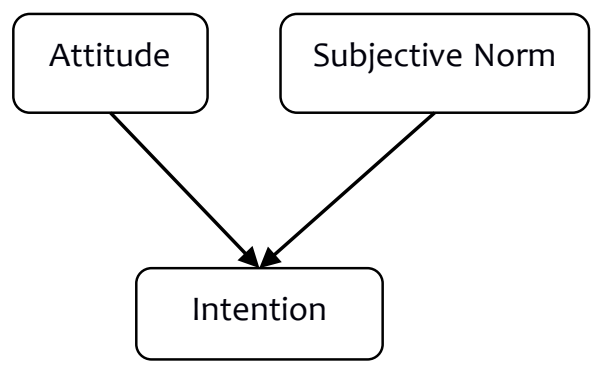

Fig 1 Theory of Reasoned Action (TRA)

\section{A. Attitude}

[14] clearly explains that the attitude cannot be directly observed but can be deduced through subject's introspection. This definition is explained further by [9] which explain that attitude represents an individual's general feeling of positive or negative evaluation towards performing a particular behaviour. Attitude is a reliable variable to predict intentions and behaviours [15]-[17]. As an example, [18] mentions that attitude is significant in directly influencing the intention to participate in Takaful scheme. Furthermore, attitude is significant and has a positive effect on paying alms [17] meanwhile [16] found that there is a significant relationship between positive attitude towards purchasing halal food that leads to the intention for halal food purchasing.

Based on cryptocurrency perspective, the profit from Bitcoin investment and politically charged aspirations that inspire the people to invest in Bitcoin [19]. The data from [20] showed that the price of Bitcoin has surged more than $1000 \%$ in less than two years. The volume of transaction also increase compared to precedence transaction before technical breakout on the cryptocurrency price. The multifold returns attract more investors as the positive attitude will lead to intention in cryptocurrency investment [21]. Apart from that, the peer-to-peer electronic cash transfer without the intervention of the third party such as financial institution helps the people to have a positive attitude and being involved in cryptocurrency market [22]. [23] identify that the attitude towards cryptocurrency buying especially Bitcoin is buyer motivated. Illegal products trading and transaction, money laundering/ tax avoidance, hedging for hyper-inflation currency and pure speculations are the main reasons that escalated the Bitcoin price recently.. In fact, the transaction is traceable between the parties involved but the decentralization network in cryptocurrency has made it hard for the financial authority to trace and keep the record for the transaction [24].

Last but not least, the amazing return from cryptocurrency investment, the society has been stoking with fear of missing out (FOMO) symptom [25]. Their attitude towards cryptocurrency investment become more irrational due to a hastened decision made. As the investors perceive that the price of the cryptocurrency will be going up, they will not hesitantly buy as much as they can to maximize the profit from price appreciation. In reality, the risk for cryptocurrency investment is very high due to no real assets owned by the investors. The profit could only be gained through price appreciation. It is not like the traditional investment which has the dividend and capital gain. However, when the investors perceive positively to the profits involved, which is the main driver to their belief and action, they are tempted to buy more cryptocurrency without giving too much concern about the risk involved. The more positive attitude towards cryptocurrency investment, the more likely the investors' intention to buy the cryptocurrency will be.

\section{CONCEPTUAL MODEL}

Figure 2 illustrates the theoretical framework of the study that enlightens the relationship between attitudes, subjective norm, financial risk tolerance and perceived benefits towards the intention to invest in cryptocurrency. This section attempts to discuss the role of attitude, 
subjective norm, financial risk tolerance and perceived benefits on consumer decision making from various perspectives and tries to link those variables with the intention to invest in cryptocurrency investment.

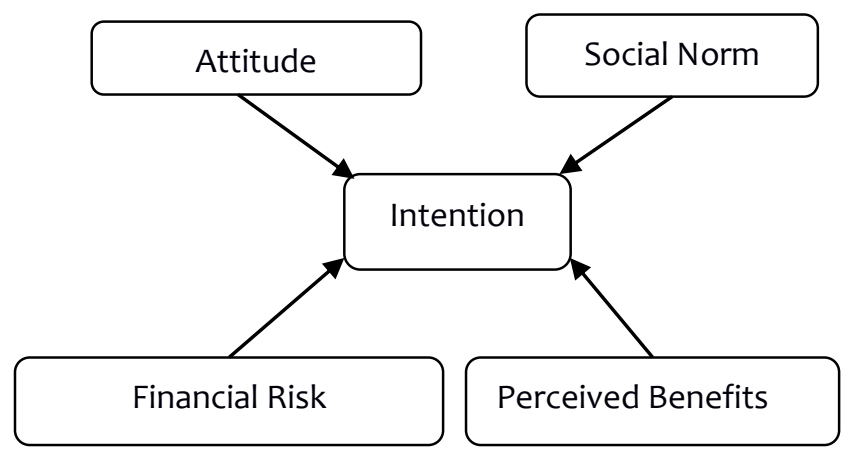

Fig2 . Theoretical Framework

\section{B. Subjective Norm}

Subjective norm is also a function of beliefs that represents an individual's perception of the most important people thinks that he or she should perform the behaviour [9] These beliefs that underlying person's subjective norm are known as normative belief. In other words, subjective norms could be explained by the person's belief about the thinking of the others on specific behaviours. [26] found that the subjective norm is highly influenced by the normative belief and motivation to comply with the society. Their findings mentioned that subjective norm is one of the main variables in influencing the intention of the society to adopt Islamic banking services in Malaysia.

Moreover, the recent surge in cryptocurrency especially led by Bitcoin has attracted more investors to jump on the bandwagon [27]. They either get the information from the social media or follow their fellow investors blindly. The 20 years old Norwegian's story who has discovered his longforgotten Bitcoin was worth a lot of thousands, then he traded for an apartment, becomes an inspirational story for cryptocurrency investors to follow his footstep [25]. Nonetheless, since all the close friends and relatives are profiting from cryptocurrency investment, one may react promptly to be acknowledged in the society. Subjective norms can lead to intention to invest in cryptocurrency as the same way the people around them are behaving. On the other hand, subjective norms may lead to herd mentality which can significantly affect the investment decision on cryptocurrency [28]. The price will rally when more people are following each other to invest in cryptocurrency and vice versa. The price will create bubble when it reaches certain level when no one can afford to buy the coin anymore. When the bubble cannot find a buyer on that level, it will start to burst and will cause the price to decline in the blink of the eye. The bubble consequence is a disaster to the investors who are hoping to make quick bucks in a short of time without proper plan and follow the friend blindly. Moreover, most people feel safe when they behave according to social norms rather than being different. Losing together is easier to forget since all the people in the society are losing, not losing alone [29]. People are easier to be influenced in the way that the community surround them are expecting them to behave. In sum, subjective norms are one of the influential variables that lead to the intention for cryptocurrency investment.

\section{Financial Risk Tolerance}

Financial risk tolerance refers to the willingness of someone to engage in financial behaviour with uncertain outcomes [30]. Jacobs-Lawson and Hershey [31] argued that the concept of risk tolerance varies depending on the context of studies such as physical danger risk, risk in everyday life or risk in gambling. Following Magendans et al. [30], this study describes financial risk tolerance as the willingness of someone dealing with uncertain outcomes while investing in cryptocurrency.

Previous studies from the context of the general investment and savings literature indicate that financial risk tolerance is associated with high risk options[31], [32]. For example, croy et al., [33] found that risk tolerance is positively predicting the intention to alter the individual superannuation investment strategy. Their study reveals that the higher risk-tolerance scores someone possess, the greater risky assets they prefer. They also reject the ownership of risk-free assets. Similarly, Lemaster and Strough [32], Bannier and Neubert, [33] studied gender differences in risk tolerance and discovered that there are significant different between men and women with regards to financial risk tolerance.

In the context of online trading, Li et al. [36] found that future adopters are financial risk-lovers. The financial educators may inform the users that financial risk is associated with online trading. But, still there is a tendency for the risk-loving consumers to ignore the warning and treat them as a motivation to invest more. This indicates that those who perceived themselves as higher risk-tolerance people are still willing to invest by accepting the fact that there are a lot of uncertainties for that kind of investment.

Kannadhasan [37] investigated the role of demographics in association of financial risk tolerance (FBT) and risk-taking behaviour (FRB) among the retail investors in India. The result revealed that gender, age, occupation and income determine the level of FRT and FRB for retail investors. Under the FRT category, two types of risks an individual may face is known as incorrect classification of category and incorrect investment decision.

In the context of cryptocurrency investment, the risk and concern are beyond financial risk. It also includes the governing agency, the lack of controls of Bitcoin exchanges 
and the volatility of the price [6]. In addition, Walch [38] highlighted the operational risk in his paper. He claimed that Bitcoin is unreliable due to the package of risks such as vulnerability to bugs, attacks, lack of adoption to new releases as well as the governance problems.

The risks that have been highlighted from previous literature (Grant and Hogan [6], Walch [36]) would have significant impact towards financial outcomes. Thus, it is interesting to observe the cryptocurrency investors on their financial risk tolerance and their decision to invest in cryptocurrency. Other than financial risk tolerance, retrospective literature also mentions the role of financial benefits that lead to investing in cryptocurrency.

\section{Perceived Benefits}

Perceived benefits are defined as lower transaction fees, quicker transaction speed and information transparency [39]. The study mentions two types of perceived benefits; direct advantages and indirect advantages. Direct advantage is defined as the immediate and tangible benefits that users can benefit from online banking such as the financial benefits, faster transaction speed and information transparency. Meanwhile, the indirect advantage is defined as the benefits that are less tangible and difficult to measure. For instance, the customer is allowed to perform online trading transaction 24/7 from any part of the worlds, various investment opportunities and free services like quotation and news [39]. The classification of perceived benefits by Lee [39] however referred to online trading that is similar to the context of cryptocurrency investment as it involves the transaction over the internet. Evidently, Nian and Chuen [40] reported that Bitcoin users are benefiting from the freedom to send and received Bitcoins at any-time, anywhere and from anyone. In other words, the users have full control of Bitcoin with fewer restrictions on transactions.

Mimouni-Chaabane and Volle [41] proposed a multibenefits framework that consumer perceived from joining loyalty programs. They discovered that monetary benefits show the greatest significance for describing loyalty to the program. Despite monetary benefits, the members of loyalty programs also enjoy the nonmonetary benefits such as special treatment and recognition benefits. In a similar vein, Mimouni-Chaabane and Volle [41] found the nonmonetary factor play a significant role in motivating people to participate in a loyalty program.

In another study, Brito [42] reported that cheaper or lower transaction cost and quicker payment network influencie people demand for Bitcoin. Empirical evidence shows that higher benefit would lead to a greater intention to continue utilizing the web [43]. While from the investors' point of view, the other benefits that the investors are demanding are high returns, star ratings, cheaper entry, no exit fees, and growth prospects of the companies [44]. Thus,
Chowdhury and Mendelson [45] agreed that a currency such as Bitcoin is capable to reduce the cost and minimizes the time for such kind of payments. Besides, Bitcoin is a financial platform that can store data in a secure and universal ledger. It is also a source secure, an independent and reliable host of financial and personal information. All hypertext links and section bookmarks will be removed from papers during the processing of papers for publication. If you need to refer to an Internet email address or URL in your paper, you must type out the address or URL fully in Regular font.

\section{RESEARCH METHODOLOGY}

The data for pilot study was gathered via online survey. The researcher prepared the questionnaire using the Google Docs and forwarded the online survey link to the target respondent through email. The target respondents for this study are those who have the basic knowledge of cryptocurrency investment. The process of data collection for pilot testing takes approximately 3 weeks. It started in the first week of May and ended in the third week of May. The researcher managed to get 45 samples for pilot testing. The data was analysed using the SPSS Version 13.

\section{FINDINGS}

There are five variables for this study. Intention to invest in Bitcoin is the dependent variable while attitude, subjective norm, financial risk tolerance and perceived benefit represent the independent variables. The first analysis conducted is reliability analysis. The reliability analysis was carried out to examine the internal consistency of the variables. The variable considered reliable if Cronbach's alpha coefficient at 0.5 or higher [46]. Table I shows the reliability test results; all the studied variables value exceed the threshold value. Thus, the reliability results indicated that the variables are valid and reliable.

\begin{tabular}{|l|c|c|}
\hline \multicolumn{1}{|c|}{ VABLE I RELIABLE TEST } \\
\hline Attitude & $\begin{array}{c}\text { Cronbach's } \\
\text { alpha }\end{array}$ & $\begin{array}{c}\text { No. of } \\
\text { Items }\end{array}$ \\
\hline Subjective norm & 0.958 & 4 \\
\hline Financial risk tolerance & 0.856 & 5 \\
\hline Perceived benefit & 0.833 & 5 \\
\hline
\end{tabular}

After performing reliability test, factor analysis was performed to explain the correlations and inter-relationship within the studied variables. Factor analysis is a data reduction technique that utilises correlations between variables [47]. For factor analysis, this study used principal component analysis, the varimax and Kaiser normalize rotation method until the eigen value for each factor is equal to 1 or more. The Kaiser-Meyer-Olkin (KMO) measures the combination of independent items, KMO value for this study is 0.846 and the Bartlett's sphericity shows a $\chi^{2}$ of 454.998 
with a significance level of 1 per cent. Thus, the sampling adequacy is greater than 0.5 which explains that the sampling is satisfactory [47]. All factor loadings extracted between 0.558 and 0.914 .

Table I FACTOR LOADINGS

\begin{tabular}{|c|c|c|c|c|}
\hline & \multicolumn{4}{|c|}{ Factor loadings } \\
\hline & Factor 1 & Factor 2 & Factor 3 & Factor 4 \\
\hline ATT2 & 0.914 & & & \\
\hline ATT1 & 0.885 & & & \\
\hline ATT3 & 0.861 & & & \\
\hline ATT4 & 0.830 & & & \\
\hline $\mathrm{PB} 5$ & 0.656 & & & \\
\hline PB4 & & 0.809 & & \\
\hline PB3 & & 0.785 & & \\
\hline PB2 & & 0.558 & & \\
\hline FRT2 & & & 0.827 & \\
\hline FRT1 & & & 0.815 & \\
\hline FRT5 & & & 0.682 & \\
\hline $\mathrm{SN}_{4}$ & & & & 0.883 \\
\hline $\mathrm{SN}_{3}$ & & & & 0.757 \\
\hline $\mathrm{SN}_{5}$ & & & & 0.700 \\
\hline Eigenvalue & 7.00 & 1.707 & 1.328 & 0.939 \\
\hline \multicolumn{5}{|c|}{ KMO measure of sampling adequacy } \\
\hline $\begin{array}{l}\text { Variance } \\
\text { explained }\end{array}$ & $49 \cdot 99$ & 12.19 & 9.48 & 6.70 \\
\hline $\begin{array}{l}\text { Bartlett's test } \\
\text { of Sphericity }\end{array}$ & \multicolumn{4}{|c|}{ Chi-square 454.998. (df, 66; $p=0.000)$} \\
\hline \multicolumn{5}{|c|}{$\begin{array}{l}\text { Notes: } \mathrm{ATT}=\text { Attention; } \mathrm{SN}=\text { Subjective Norm; FRT= Financial Risk } \\
\text { Tolerance; } \mathrm{PB}=\text { Perceived Benefit }\end{array}$} \\
\hline
\end{tabular}

\section{CONCLUSIONS}

The objective of this study is to identify the factors that influence the intention to invest in Bitcoin. The data gathered from the 45 samples and was analysed using the SPSS programme. The results of the reliability test indicated that the items are valid and reliable to represent the intention to invest in Bitcoin. On the other hand, the exploratory factor analysis also shows that the model is significant and satisfactory. Thus, this study suggests that in general attitude, subjective norm, financial risk-tolerance and perceived benefits lead to the intention to invest in Bitcoin. Taking all together, this study suggests that Bitcoin is entering a new phase and is widely accepted as a mode of investments and payments. The study has its own purpose towards enhancing our understanding towards the intention to invest in Bitcoin. This study contributes to the existing literature by developing a valid instrument that measures the intention to invest in bitcoin. On the other hand, this study adapted the TRA to explain the relationship between variables and the intention to invest in Bitcoin. Future research should consider the perceived behavioural control to observe the actual behaviour of Bitcoin investment. Being limited preliminary analysis, this study lacks competent empirical evidence to confirm the relationships between the studied variables. Therefore, an adequate and bigger sample is needed for future work to establish the empirical support of the association of the studied variables.

\section{REFERENCES}

[1] J. Bohr and M. Bashir, "Who Uses Bitcoin?," in 2014 Twelfth Annual Conference on Privacy, Security and Trust (PST), 2014, pp. 94-101.

[2] L. H. White, “The Market for Cryptocurrencies," Hofstra Law Rev., vol. 35, no. 2, pp. 383-402, 2015.

[3] H. Vranken, "Sustainability of bitcoin and blockchains," Curr. Opin. Environ. Sustain., vol. 28, pp. 1-9, 2017.

[4] “Confirmed Transactions Per Day," blockchain.info, 2018. [Online]. Available: https://blockchain.info/en/charts/n-transactions. [Accessed: 25-Apr-2018].

[5] A. Urquhart, “The inefficiency of Bitcoin," Econ. Lett., vol. 148, pp. 17, 2016.

[6] G. Grant and R. Hogan, "Bitcoin: Risks and Controls," J. Corp. Account. Financ., vol. 26, no. 5, pp. 29-35, 2015.

[7] R. Böhme, N. Christin, B. Edelman, and T. Moore, "Bitcoin : Economics , Technology , and Governancet," Am. Econ. Assoc., vol. 29, no. 2, pp. 213-238, 2015.

[8] F. M. Taib, T. Ramayah, and D. A. Razak, "Factors influencing intention to use diminishing partnership home financing," Int. J. Islam. Middle East. Financ. Manag., vol. 1, no. 3, pp. 235-248, 2008.

[9] M. Fishbein and I. Ajzen, Belief, attitude, intention and behavior: An introduction to theory and research. Reading: Addison-Wesley, 1975.

[10] M. Abduh, J. Duasa, and M. Omar, "Factors Influence Depositors' Withdrawal Behavior in Islamic Banks: A Theory of Reasoned Action," Int. J. Hum. ..., vol. 5, no. 12, pp. 2074-2079, 2011.

[11] S. Lada, G. H. Tanakinjal, and H. Amin, "Predicting intention to choose halal products using theory of reasoned action," Int. J. Islam. Middle East. Financ. Manag., vol. 2, no. 1, pp. 66-76, 2009.

[12] A. Mukhtar and M. Mohsin Butt, "Intention to choose Halal products: the role of religiosity,” J. Islam. Mark., vol. 3, no. 2, pp. 108-120, 2012.

[13] D. Abdul Razak and M. Abduh, "Customers ' Attitude towards Diminishing Partnership Home Financing in Islamic Banking," Am. J. Appl. Sci., vol. 9, no. 4, pp. 593-599, 2012.

[14] R. Agheyisi and J. A. Fishman, "Language Attitude Studies: A Brief Survey of Methodological Approaches," English, vol. 12, no. 5, pp. 137-157, 1970.

[15] I. Ajzen, "The theory of planned behaviour: Reactions and reflections," Psychology and Health, vol. 26, no. 9, pp. 1113-1127, 2011.

[16] S. Shah Alam and N. Mohamed Sayuti, "Applying the Theory of Planned Behavior (TPB) in halal food purchasing," Int. J. Commer. Manag., vol. 21, no. 1, pp. 8-20, 2011.

[17] N. Huda, N. Rini, Y. Mardoni, and P. Putra, "The Analysis of Attitudes, Subjective Norms, and Behavioral Control on Muzakki's Intention to Pay Zakah,” Int. J. Bus. Soc. Sci., vol. 3, no. 22, pp. 271-279, 2012.

[18] M. M. Husin and A. A. Rahman, "Do Muslims intend to participate in Islamic insurance? Analysis from theory of planned behaviour," J. Islam. Account. Bus. Res., vol. 7, no. 1, pp. 42-58, 2016.

[19] A. Yelowitz and M. Wilson, "Characteristics of Bitcoin users : an analysis of Google search data," Appl. Econ. Lett., vol. 22, no. 13, pp. 1030-1036, 2015.

[20] Investing.com, "Bitcoin Price Chart, Market Cap, Index and News Investing.com," 2018. .

[21] X. Li and C. A. Wang, "The technology and economic determinants of cryptocurrency exchange rates: The case of Bitcoin," Decis. Support Syst., vol. 95, pp. 49-60, 2017.

[22] S. Nakamoto, "Bitcoin: A Peer-to-Peer Electronic Cash System," Www.Bitcoin.Org, p. 9, 2008.

[23] E. Pichet, “Bitcoin: Speculative Bubble or Future Value?," pp. 1-6, 2017. 
[24] F. Tschorsch and B. Scheuermann, "Bitcoin and beyond: A technical survey on decentralized digital currencies," IEEE Commun. Surv. Tutorials, vol. 18, no. 3, pp. 2084-2123, 2016.

[25] N. Popper, "The Rush to Coin Virtual Money With Real Value," no. November, pp. 1-9, 2013.

[26] A. Echchabi and O. N. Olaniyi, "Using Theory of Reasoned Action to Model the Patronisation Behaviour of Islamic Banks' Customers in Malaysia,” Res. J. Bus. Manag., vol. 6, no. 3, pp. 70-82, 2012.

[27] X. Gao, G. D. Clark, and J. Lindqvist, "Of Two Minds, Multiple Addresses, and One History: Characterizing Opinions, Knowledge, and Perceptions of Bitcoin Across Groups," pp. 1-21, 2015.

[28] B. Vockathaler, "The Bitcoin Boom: An In Depth Analysis Of The Price Of Bitcoins," pp. 1-75, 2015.

[29] [29]A. K. Chaudhary, "Impact of Behavioral Finance in Investment Decisions and Strategies - a Fresh Approach," Int. Jounal Manag. Res. Bus. Strateg., vol. 2, no. 2, pp. 84-93, 2013.

[30] [30]J. Magendans, J. M. Gutteling, and S. Zebel, "Psychological determinants of financial buffer saving: the influence of financial risk tolerance and regulatory focus," J. Risk Res., vol. 20, no. 8, pp. 1076$1093,2017$.

[31] J. M. Jacobs-Lawson and D. A. Hershey, "Influence of future time perspective, financial knowledge, and financial risk tolerance on retirement saving behaviors," Financ. Serv. Rev., vol. 14, no. August, pp. 331-344, 2005

[32] J. Gilliam, S. Chatterjee, and J. Grable, "Measuring the Perception of Financial Risk Tolerance : A Tale of Two Measures," J. Financ. Couns. Plan., vol. 21, no. 770, pp. 30-43, 2010.

[33] G. Croy, P. Gerrans, and C. Speelman, "The role and relevance of domain knowledge , perceptions of planning importance, and risk tolerance in predicting savings intentions," J. Econ. Psychol., vol. 31, no. 6, pp. 860-871, 2010.

[34] P. Lemaster and J. Strough, "Beyond Mars and Venus: Understanding gender differences in financial risk tolerance," J. Econ. Psychol., vol. 42, pp. 148-160, 2014.

[35] C. E. Bannier and M. Neubert, "Gender differences in financial risk taking: The role of financial literacy and risk tolerance," Econ. Lett. vol. 145, pp. 130-135, 2016.
[36] Y. M. Li, J. Lee, and B. J. Cude, "Intention To Adopt Online Trading: Identifying The Future Online Traders," 2002 Assoc. Financ. Couns. Plan. Educ., 2002.

[37] M. Kannadhasan, "Retail investors' financial risk tolerance and their risk-taking behaviour: The role of demographics as differentiating and classifying factors," IIMB Manag. Rev., vol. 27, no. 3, pp. 175-184, 2015.

[38] A. Walch, "The Bitcoin Blockchain as Financial Market Infrastructure: A Consideration of Operational Risk," Legis. Public Policy, vol. 18, pp. 837-894, 2015.

[39] M. C. Lee, "Predicting and explaining the adoption of online trading: An empirical study in Taiwan," Decis. Support Syst., vol. 47, no. 2, pp. 133-142, 2009.

[40] L. P. Nian and D. L. K. Chuen, Introduction to Bitcoin. Elsevier Inc., 2015.

[41] A. Mimouni-Chaabane and P. Volle, "Perceived benefits of loyalty programs: Scale development and implications for relational strategies," J. Bus. Res., vol. 63, no. 1, pp. 32-37, 2010.

[42] J. Brito, "Benefits and Risks of Bitcoin for Small Businesses," 2014

[43] R. Wei, "Wi-Fi powered WLAN: When built, who will use it? Exploring predictors of wireless internet adoption in the workplace," J. Comput. Commun., vol. 12, no. 1, pp. 155-175, 2006.

[44] M. Brimble, V. Vyvyan, and C. Ng, "Belief and Investing : Preferences and Attitudes of the Faithful," Australas. Account. Bus. Financ. J., vol. 7, no. 1, pp. 23-43, 2013.

[45] A. Chowdhury and B. K. Mendelson, "Digital Currency and Financial System: The Case of Bitcoin The Case of Bitcoin," Investments Wealth Monit., no. April, pp. 40-56, 2014.

[46] F. N. Kerlinger and H. B. Lee, Foundations of Behavioral Research. Orlando: FL: Harcourt College Publishers., 2000.

[47] H. Amin, A. rahim Abdul Rahman, and D. Abdul Razak, "Consumer acceptance of Islamic home financing," Int. J. Hous. Mark. Anal., vol. 7, no. 3, pp. 307-332, 2014 